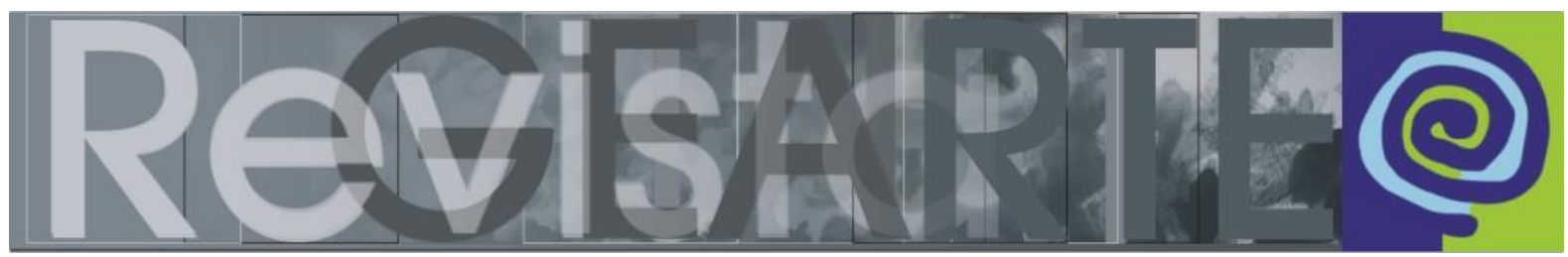

e-ISSN 2357-9854

\title{
Abordagem Triangular e as narrativas de si: autobiografia e aprendizagem em Arte
}

\author{
Lucia Gouvêa Pimentel (Universidade Federal de \\ Minas Gerais - UFMG, Belo Horizonte/ MG, Brasil)
}

\begin{abstract}
RESUMO - Abordagem Triangular e as narrativas de si: autobiografia e aprendizagem em Arte - As perspectivas Arte/Educativas da Abordagem Triangular extrapolam o campo das artes e indicam possibilidades de pesquisas em outros campos, que também contribuam tanto para a formação do Professor de Arte quanto para a prática arte/educativa. Considerando que os estudos em autobiografia tratam de questões importantes para que o Arte/Educador possa conhecer melhor a si mesmo e entender as narrativas que os educandos fazem a respeito de sua vida, seus desejos, emoções e sentimentos, é importante que o Arte/Educador de Arte saiba buscar informações sobe como promover desafios de aprendizagem que propiciem o pensamento artístico. Relacionar as teorias de Ana Mae Barbosa e Christine Delory-Momberger pode ajudar o Arte/Educador a rastrear ligações entre a aprendizagem em Arte e as metodologias que são criadas para seu ensino, auxiliando-o nas suas decisões docentes.
\end{abstract}

PALAVRAS-CHAVE

Abordagem Triangular. Autobiografia. Ensino/aprendizagem em Arte.

ABSTRACT - Triangular Approach and self-narratives: autobiography and learning in Art - The Triangular Approach in Art and Education extends beyond the field of the arts in order to indicate possibilities for research in other fields that may also contribute both to the training of art teachers and to artistic and educational practice. Given that autobiographical studies tackle important questions that enable teachers to know themselves better and to understand the lives of students, in particular their desires, emotions and feelings, it is essential that art teachers seek information about ways of challenging learners to think more deeply about art. Between them, the theories of Ana Mae Barbosa and Christine Delory-Momberger can help teachers both to make all sorts of links between learning about art and pedagogical methodologies and to help them in the decisions they make as teachers.

KEYWORDS

Triangular Approach. Autobiography. Art teaching and learning.

\section{Introdução}

A Abordagem Triangular sistematizada por Ana Mae Barbosa, na década de 1980 - que já está ziguezagueando e alcançando outras dimensões - tem como uma de suas premissas e uma dentre as inúmeras possibilidades de ampliar o campo da tarefa de arte/educar a questão do não estreitamento de seus limites e consequente alargamento para interação com outros campos do conhecimento. Nesse sentido, considera-se que todas as ações que tiverem a Abordagem Triangular como fonte de referência e a experiência como base podem ser consideradas vivências 
arte/educativas, ou seja, são passíveis de participarem da construção de metodologias de ensino/aprendizagem em Arte. É importante ressaltar que são o Professor de Arte e o Arte/Educador quem constrói a metodologia, quer seja por ter conhecimento de métodos, ou por registrar suas ações em sala de aula e refletir sobre elas, tornando-as princípios para a criação de suas metodologias. A divulgação dessas ações e suas reflexões, seja em congressos ou eventos similares ou em divulgação via internet é importante para detonar novas propostas por parte de outros Professores de Arte, Arte/Educadores e estudantes de Licenciatura nas várias modalidades artísticas.

Considerando que as ações principais da Abordagem Triangular - fruir, contextualizar e fazer (não necessariamente nesta ordem) estão intimamente relacionadas entre si de forma dinâmica e retroalimentadora, é importante que se tenha a clareza dos fundamentos de cada uma delas, para que se possa buscar em outros campos do conhecimento teorias que auxiliem em propostas arte/educativas consistentes.

Neste texto, considera-se que essas três ações são impulsionadas por um sujeito individual em compartilhamento com o sujeito coletivo, ora o individual sendo o impulsionador, ora o coletivo preponderando. Não se faz julgamento de valor quanto a isso, pois ambos os sujeitos - individual e coletivo - têm importância e protagonismo no ato de arte/educar. O que será discutido, aqui, vai na direção de tentar identificar fatores de aprendizagem de si, em relação ao respeito à intimidade e à comunidade, e o compartilhamento dessa aprendizagem como fator de construção social da comunidade de aprendizagem em Arte. Opta-se pelo viés da pesquisa autobiográfica, por considerar ser esta uma possível via de estudo e pesquisa que pode colaborar com a construção de conhecimentos em Arte e com o pensamento artístico.

\section{Autobiografia ou as narrativas de si}

A atividade biográfica engloba várias maneiras de configuração, podendo-se dizer que ela se apresenta conforme as necessidades de apresentação de si mesmo que o sujeito tem. Assim, para postular um emprego, ele organiza seu curriculum vitae indicando o que é mais pertinente para o cargo que pleiteia; para se apresentar nas 
redes sociais divulga o que pode lhe trazer retorno positivo de amigos e parentes; para iniciar uma conversa fala sobre algo que lhe desperta interesse etc.

Da mesma forma, na escola, escolhe um script de si para as diversas ocasiões ou situações em que se encontra. As aulas de Arte deveriam ser o espaço onde mais o aluno e o arte/educando pudessem expor livremente suas ideias sobre seus desejos, suas curiosidades, suas descobertas, sua vida e seus pensamentos artísticos, deixando de lado a tentativa de agradar o professor ou o arte/educador para ter boas notas ou aprovar seu trabalho. Para que isso ocorra, é necessário que o professor e o arte/educador tomem a iniciativa de abrir esse espaço de forma transparente e compartilhada, cuidando para que, sem deixar de lado sua responsabilidade de ser o professor ou o arte/educador, propicie experiências e ações em que o aluno e o arte/educando se relacionem com suas vivências pessoais e sociais, provocando uma atitude mental e comportamental significativa para a vida.

A narrativa de si não é relato do que se passa com alguém, mas a construção de como o sujeito se percebe e se apresenta; é um processo contínuo que não se fixa em um papel ou em um arquivo digital, não é somente um discurso, mas algo que deixa marcas e memórias em fluxo. Mais que escrever ou gravar palavras e sons, é firmar compromissos de vida consigo mesmo e com quem compartilha sua vida.

Portanto, na autobiografia, o fator individual e o fator social estão intrinsecamente relacionados.

Nessa interface do individual e do social - que só existem um por meio do outro, que estão num processo incessante de produção recíproca - o espaço da pesquisa biográfica consistiria então em perceber a relação singular que o indivíduo mantém, pela sua atividade biográfica, com o mundo histórico e social e em estudar as formas construídas que ele dá à sua experiência. Para dizê-lo de modo mais sintético: o objeto visado pela pesquisa biográfica, mediante esses processos de gênese socioindividual, seria o estudo dos modos de constituição do indivíduo enquanto ser social e singular (DELORYMOMBERGER, 2003, 2005). Essa é, então, a singularidade que a pesquisa biográfica se dá por tarefa apreender, mas não é uma singularidade solipsista, é uma singularidade atravessada, informada pelo social, no sentido em que o social the dá seu quadro e seus materiais. (DELORYMOMBERGER, 2012b, p. 524). 
O atravessamento a que se refere a autora, em princípio, não é controlável, mas, no âmbito escolar, é passível de ser conduzido de modo a que a aprendizagem em Arte se torne significativa.

\section{Abordagem Triangular e as narrativas de si}

A Abordagem Triangular é uma proposta pós-moderna de Arte/Educação que dá margem à ampliação de limites e fronteiras, tanto as de cunho cultural quanto as interdisciplinares para o estudo da Arte. Considera-se que as aulas de Arte devem ser momentos privilegiados para exercitar o pensamento artístico. Assim sendo, é preciso que essas aulas sejam diversificadas, tanto em relação às atividades quanto em relação aos conceitos e fundamentações teóricas e técnicas necessárias à construção de conhecimento em Arte.

O pensamento artístico e a construção de conhecimento em Arte estão intrinsecamente imbricados com as formas como as pessoas se pensam e se conhecem, já que a Arte não está dissociada das intenções pessoais e sociais do sujeito. Aportar as narrativas de si, tanto para a formação do professor de Arte (ou do arte/educador) quanto para a criação das metodologias de ensino/aprendizagem em Arte, portanto, pode ser de grande valia tanto para professores e arte/educadores, quanto para alunos e arte/educandos.

Em sua interface com a Abordagem Triangular, as narrativas de si têm estreita relação com as três ações basilares: no fazer, no fruir e no contextualizar, sendo que o fazer visa propiciar uma rede de construção de conhecimentos baseados no contato direto com experimentações estéticas; o fruir visa propiciar outras percepções do objeto, ou seja, a fruição pressupõe conhecimento e consequente correlação de elementos contextuais; o contextualizar visa estabelecer relações pela compreensão histórica, social e cultural da Arte nas sociedades.

No fazer, a expressão e a experimentação são as mostras mais evidentes, pois, além dos exercícios - que são importantes para o conhecimento de materiais, técnicas e tecnologias -, as propostas de ações artísticas cumprem um papel fundamental para as construções de conhecimento propiciadas pela imersão em si e 
na relação com os materiais, técnicas e tecnologias. Para a construção da narrativa de si, também é necessária a imersão do sujeito em seu íntimo, apropriando-se das memórias de fatos e de sensações vivenciadas.

No fruir, pelo envolvimento sensório-cognitivo com a Arte, são ativados movimentos de imaginação e de relações com a memória e com as marcas das vivências artísticas, que promovem a interligação entre o que ocorre no momento da fruição e as informações e os saberes apreendidos anteriormente. É preciso que o professor e o arte/educador saibam identificar quais objetos artísticos podem ampliar o cabedal de referências estéticas que os alunos e arte/educandos já possuem, e como é necessário agir para que os educandos se sintam motivados a explorar o que Ihes é apresentado. Pedir que os alunos e arte/educandos façam sua autobiografia pode ajudar, em muito, nessa tarefa.

No contextualizar, em que o desafio é selecionar, dentre os saberes e conhecimentos já construídos, quais são importantes para uma nova construção que realmente façam sentido para quem os está construindo e para seus pares no processo de ensino/aprendizagem, entender como os alunos e arte/educandos se relacionam consigo mesmos e com os outros auxilia o professor ou o arte/educador a determinar quais os pontos de contato mais propícios para o trabalho.

Parte-se do princípio que a aprendizagem em Arte não é somente parte do que o sujeito sabe dos outros e das coisas, mas também é fator essencial para que ele saiba de si próprio. Não se está considerando que ele tenha que fazer um discurso de si próprio, sobre artistas ou sobre objetos artísticos, mas sim que ele entenda corporeamente os sentidos intrínsecos aos fatos, aos artistas, aos objetos artísticos. Afinal, conhecer Arte não é somente saber dizer algo sobre Arte, mas sim deixar-se afectar por algo que é disponibilizado e que é significativo para a vida humana, e poder disponibilizar algo que seja artístico para que outras pessoas possam vivenciar o mesmo processo e também contribuir socialmente.

Esse conhecimento pode ter formas várias para ser disponibilizado, como informação ou desafio para as outras pessoas. Podem ser gestos, sons, traços, volumes, palavras etc., e não somente palavras. É a diversidade de formas de 
divulgação que poderá desafiar outras pessoas para que, a partir dessa informação, elas se inquietem, movam-se internamente, busquem outras vivências e, a partir daí, construam novos conhecimentos e explorem outras experiências. É essa a força motriz da aprendizagem em Arte, que não se dá apenas por transmissão de informações de conteúdos ou atividades esporádicas com materiais ditos "artísticos".

\begin{abstract}
A Abordagem Triangular é, portanto, um referencial, uma possibilidade concreta de trabalho complexo em arte/educação; cabe ao arte/educador levar em consideração as diversas possibilidades de expressão abordadas pela abrangência dos objetos artísticos e as especificidades educacionais de formação que pontue como relevantes (PIMENTEL, 2010, p. 212).
\end{abstract}

Pode-se dizer que a abertura que a Abordagem Triangular oferece como referencial incita o professor de Arte e o arte/educador a buscarem, em sua própria vivência, trilhas por onde andaram e de que formas elas foram trilhadas para, a partir delas, elaborar propostas que sejam significativas para alunos e arte/educandos.

\title{
Abordagem Triangular e as narrativas de si
}

Delory-Momberger (2012a) define individualização social como sendo "[...] a resultante de uma configuração particular, própria das sociedades modernas [...]", que não deve ser confundida com o egocentrismo do indivíduo que se volta para si mesmo. A autora trabalha com a abordagem inversa à da contraposição de indivíduo e sociedade, indicando que a individualização social "[...] deve ser considerada como o produto conjunto da determinação e da criatividade social [...]" (DELORY-MOMBERG, 2012a, p. 21-22).

Esse produto conjunto permite que os indivíduos sejam os construtores de sua própria individualidade, ao mesmo tempo que, com ela, constituem a sociedade. Nesse sentido, quanto mais cada indivíduo sabe de si mesmo e de como pode contribuir para a sociedade, mais a sociedade se beneficiará com sua individualização. O exercício da autobiografia pode contribuir para que esse entendimento de si mesmo e de sua participação social seja coerente com o que ele considera ser um bem social.

Se arte/educar é "[...] influir positivamente no desenvolvimento cultural dos estudantes por meio do conhecimento de arte que inclui a potencialização da 
recepção crítica e a produção. " (BARBOSA, 2005, p. 98), e se "[...] a dimensão de experiência e aprendizagem de si não é dissociável da experiência e da aprendizagem dos mundos sociais." (DELORY-MOMBERGER, 2012a, p. 89) dos quais se participa, infere-se que as narrativas de si têm muito a contribuir com os processos de arte/educar.

Assim, principalmente em relação ao que se considera, por parte dos alunos e arte/educandos, é que "[...] a condição biográfica é indissociável de uma forma de sociedade na qual as grandes questões formulam-se, cada vez mais, em termos de identidade e de reconhecimento [...]" (DELORY-MOMBERGER, 2012a, p. 64). Temse, então, que a falta de vivência significativa em Arte pode levar à dificuldade da narrativa de si, uma vez que o sujeito fica alijado de experimentações que o ajudariam a se conhecer e se expressar e, portanto, de saber se apresentar e saber das imagens e emoções que ele próprio veicula de si.

Já em relação aos professor e arte/educadores, "[...] as lutas, como as resistências, organizam-se em torno do reconhecimento social dos valores de respeito e de dignidade das pessoas e de sua expressão política na 'comunidade dos cidadãos' [...]" (DELORY-MOMBERGER, 2012a, p. 64). As lutas e as resistências dos arte/educadores, portanto, vão em direção ao reconhecimento social não se si mesmos, mas do que, a partir do conhecimento de si mesmos, pleiteiam como respeito e dignidade das pessoas, ou seja, no que se deve considerar como formação humana dos sujeitos arte/educandos sob sua responsabilidade.

A vivência em aprendizagem em Arte e Arte/Educação propicia a construção da narrativa autobiográfica que objetiva terminar com a exclusão, a indiferença, o desdém e o desprezo a que estão submetidos os alunos e os arte/educandos que não têm respeitado seu direito à educação em Arte. Incluir na narrativa de vida dos alunos e arte/educandos as experiências em Arte é essencial para que eles possam se apresentar como sujeitos partícipes importantes da vida social e sabedores de suas potencialidades.

Ressalte-se que o que se busca é o diálogo entre ações intrínsecas para o trabalho com Arte/Educação, propondo a articulação entre abordagens não 
conflitantes entre indivíduo e sociedade, entre Arte e Educação, mas compartilhadas no entrelaçamento de possibilidades de construção de um sujeito atuante e crítico, que saiba se posicionar perante si mesmo e perante as sociedades das quais participa, quer seja como estudante, colega ou professor.

A tarefa de arte/educar não diz respeito a estratificações hierarquizadas do objeto artístico, uma vez que "[...] não se tratam de fases da aprendizagem, mas de processos mentais que se interligam para operar a rede cognitiva da aprendizagem." (BARBOSA, 1998, p. 40). E, nessa rede, estão o conhecimento e as narrativas de si, uma vez que processos mentais são corpóreos, assim como a rede de aprendizagem de arte/educar lida com sujeitos interconectantes também corpóreos.

\section{Algumas considerações}

Uma importante observação que se faz é que influir positivamente engloba uma série de ações, inclusive a de partir do pressuposto de que a investigação de diversas possibilidades de abordagem da produção artística é uma das formas de construção de saberes e conhecimentos em Arte. Outra observação é que a Abordagem Triangular não se limita a si mesma. O diálogo de suas premissas com as teorias de outros autores é essencial para a construção de novas formas de pensamento e de ação de arte/educar.

\footnotetext{
Trata-se de fazer com que os indivíduos e os grupos, sejam eles quais forem, sejam reconhecidos como parceiros integrais, estejam associados e participem dos debates e das decisões que lhes dizem respeito. Uma verdadeira política do sujeito seria reinscrever o sujeito como ator na Cidade e fazer do sujeito, ao mesmo tempo uma questão ética, uma questão de democracia (DELORY-MOMBERGER, 2012a, p. 116).
}

Ou seja, trata-se de instaurar o humano na vida do aluno e do arte/educando; o humano de si mesmo para que a sociedade possa se humanizar, uma vez que Arte é uma construção cultural social, que atravessa e é atravessada pela história e pelo político, que são dimensões constitutivas da individualidade, considerando-se que político refere-se à organização de pessoas livres e com direitos e deveres iguais, que trabalham pelo bem da comunidade e têm seus direitos respeitados. 
Em um momento em que direitos sociais são substituídos por serviços, direitos humanos são arrancados abruptamente dos professores, arte/educadores, alunos e arte/educandos, necessário se faz extrair, de dentro de si, possibilidades humanas de reação consistente capazes de criar (sobre)vida, até que uma nova organização seja viável.

A narrativa de si tem a potencialidade de configurar elementos de vida e de desejos em um alinhamento expressivo, quando conduzida em aliança com abordagens educativas que privilegiam o sujeito como ator participante da aprendizagem. Nesse sentido, a Abordagem Triangular enreda ações e tece fios que trabalham o ato de arte/educar em constante narrativa de si para professores, arte/educadores, alunos e arte/educandos. Por meio da Abordagem Triangular, é possível contribuir para a ação performativa do agir humano, pois o fazer, o fruir e o contextualizar não são ações dispersas, mas interativas: enquanto se investe no fazer, é possível contextualizar e fruir; enquanto se investe no fruir, é possível fazer e contextualizar; enquanto se investe em contextualizar, é possível fruir e fazer. Conseguir realizar o pensamento em loop, detonar mudanças, conectar o mundo interior com o mundo exterior e vice-versa, enfim, conseguir expandir o sentido da vida é o que se busca, não como utopia, mas como presença.

\section{Referências}

ANDRADE, Fabrício. Arte-Educação: emoção e racionalidade. São Paulo: Annalume, 2006.

BARBOSA, Ana Mae. Tópicos utópicos. Belo Horizonte: C/Arte, 1998.

BARBOSA, Ana Mae (Org.). Arte-Educação: leitura no subsolo. São Paulo: Cortez, 2002.

BARBOSA, Ana Mae (Org.). Inquietações e mudanças no ensino da arte. São Paulo: Cortez, 2003.

BARBOSA, Ana Mae. Arte Educação Contemporânea: consonâncias internacionais. São Paulo: Cortez, 2005.

DELORY-MOMBERGER, Christine. A condição biográfica: ensaios sobre a narrativa de si na modernidade avançada. Natal: EDUFRN, 2012a.

DELORY-MOMBERGER, Christine. Abordagens metodológicas na pesquisa biográfica. Revista Brasileira de Educação, Rio de Janeiro, v. 17, n. 51, p. 523-740, set./dez. 2012b.

PIMENTEL, Lucia Gouvêa. Fruir, contextualizar e experimentar como possível estratégia básica para investigação e possibilidade de diversidade no ensino de Arte: o contemporâneo de vinte anos In: BARBOSA, Ana Mae; CUNHA, Fernanda Pereira da (Org.). Abordagem Triangular no ensino das artes e culturas visuais.1 ed. São Paulo: Cortez, 2010, p. 211-228.

PIMENTEL, Lucia Gouvêa. Fugindo da escola do passado: arte na vida. Revista Digital do LAV, v.8, n.2, p. 5-17, maio/ago. 2015a. 
PIMENTEL, Lucia Gouvêa. Processos artísticos como metodologia de pesquisa. Ouvirouver (Online), v.11, n.1, p. 88-98, jan./jun. 2015b.

PIMENTEL, Lucia Gouvêa. A prática artística docente como metodologia para a formação de professores. Revista CLEA, v. 1, p. 50-57 maio/jun. 2016.

\section{Lucia Gouvêa Pimentel}

Professora Titular da Escola de Belas Artes da UFMG, Coordenadora Adjunta da área de Artes Mestrado Profissional/CAPES e Conselheira do Instituto Arte das Américas. Bacharel e Licenciada Artes Visuais (UFMG), Mestre em Educação (UFMG), Doutora em Artes (USP). É líder do Grupo de Pesquisas Ensino da Arte e Tecnologias Contemporâneas (CNPq), Editora da Revista CLEA, membro da Equipe Editorial do Art Research Journal - ARJ, Coordenadora da Coleção Arte\&Ensino da Editora C/ARTE e membro da AMARTE, FAEB, ANPAP, CLEA e InSEA. Atua como artista, professora e pesquisadora, com ênfase em Ensino de Arte e em Gravura, atuando principalmente nos seguintes temas: Ensino de Arte, Artes Visuais, Ensino de Arte e Tecnologia, Arte/Educação, Formação de Professores, Cognição Imaginativa e Gravura.

E-mail: luciagpi@gmail.com

Currículo: http://lattes.cnpq.br/3342330120066308 